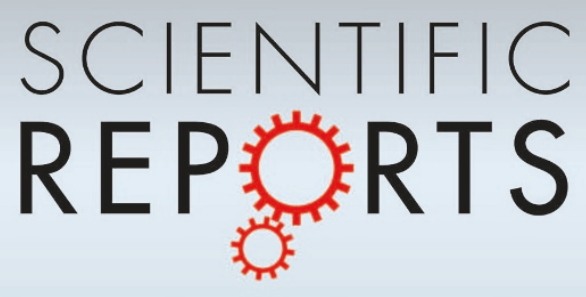

OPEN

SUBJECT AREAS:

STATISTICAL PHYSICS, THERMODYNAMICS AND NONLINEAR DYNAMICS

STATISTICS

APPLIED PHYSICS

MODELLING AND THEORY

Received

30 July 2012

Accepted

28 August 2012

Published

20 September 2012

Correspondence and requests for materials should be addressed to B.P. (bp@phy.hr)

\section{The competitiveness versus the wealth of a country}

\author{
Boris Podobnik ${ }^{1,2,3}$, Davor Horvatić ${ }^{4}$, Dror Y. Kenett ${ }^{1} \&$ H. Eugene Stanley ${ }^{1}$
}

${ }^{1}$ Center for Polymer Studies and Department of Physics, Boston University, Boston, MA 022 15, USA, ${ }^{2}$ Zagreb School of Economics and Management, 10000 Zagreb, Croatia, ${ }^{3}$ Faculty of Civil Engineering, University of Rijeka, 51000 Rijeka, Croatia, ${ }^{4}$ Physics Department, Faculty of Science, University of Zagreb, 10000 Zagreb, Croatia.

Politicians world-wide frequently promise a better life for their citizens. We find that the probability that a country will increase its per capita GDP ( $g d p)$ rank within a decade follows an exponential distribution with decay constant $\lambda=0.12$. We use the Corruption Perceptions Index (CPI) and the Global Competitiveness Index (GCI) and find that the distribution of change in CPI (GCI) rank follows exponential functions with approximately the same exponent as $\lambda$, suggesting that the dynamics of $g d p$, CPI, and GCI may share the same origin. Using the GCI, we develop a new measure, which we call relative competitiveness, to evaluate an economy's competitiveness relative to its gdp. For all European and EU countries during the 2008-2011 economic downturn we find that the drop in gdp in more competitve countries relative to gdp was substantially smaller than in relatively less competitive countries, which is valuable information for policymakers.

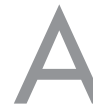

n economy's competitiveness is defined as the set of institutions, policies, and factors that determine the economy's level of productivity ${ }^{1}$. The level of productivity determines the rates of return obtained by investments in the economy, which in turn determines the economy's growth rate ${ }^{1-8}$.

Why does competitiveness in some nations increase more rapidly than in other nations? Why do some nations seem unconcerned about improving their competitiveness, even though increasing competitiveness attracts investment thus increases wealth? Whether poor countries will be able to catch up to rich countries has been a question for many years, and the varying conclusions drawn have depended on the approach taken, e.g., how many countries are involved or whether size dependence is taken into consideration ${ }^{7-13}$. Here we ask what is the probability that a poor country can become a rich country within a given time period, e.g., within a decade? How are the dynamics of competitiveness and the dynamics of a country's wealth related?

We focus on both static and dynamic aspects of competitiveness ${ }^{1}$ by examining the per capita Gross Domestic Product (GDP) ${ }^{14}$, denoted as $g d p$, and the Global Competitiveness Index (GCI) (see Methods), which quantifies the institutions, policies, and factors that control economic prosperity ${ }^{1,15}$. First we quantify the relationship between the $g d p$ and the GCI. Then we introduce a new measure to assess the competitiveness relative to $g d p$ as the difference $\mathcal{D}$ between the actual GCI value and the expected value of GCI obtained from the power-law fit between $\mathrm{GCI}$ and $g d p$ - the more negative is $\mathcal{D}$, the smaller will be the relative competitiveness of a given country. We examine how the level of competitiveness affects the dynamics of a country's wealth during a recession, finding that during the 2008-2011 period EU countries with positive $\mathcal{D}$ values experienced a significantly smaller drop in $g d p$ than countries with negative $\mathcal{D}$ values. The probability that a country will increase its wealthquantified by its rank within a decade-follows an exponential distribution. We relate this probability to the probability of change in GCI rank, and our results are consistent with the interesting possibility that the dynamics of $g d p$ and the dynamics of GCI may share the same origin.

\section{Results}

Competitiveness versus growth. Over the past decade, countries such as Switzerland, Singapore, the Nordic countries, and the USA have been considered to be the most competitive. Generally speaking, rich countries are considered to be more competitive than poor countries, implying that there is a functional dependence between GCI and $g d p$. Here we address two questions: (i) What is the expected level of competitiveness for a country with a given level of wealth? (ii) What is the probability that a country will substantially improve its wealth and its level of competitiveness?

Addressing question (i), Figs. 1(a) and 1(b) show plots of GCI versus $g d p$, both worldwide and for different European countries. We find a positive functional dependence between GCI and $g d p$, which we fit with a power law, 

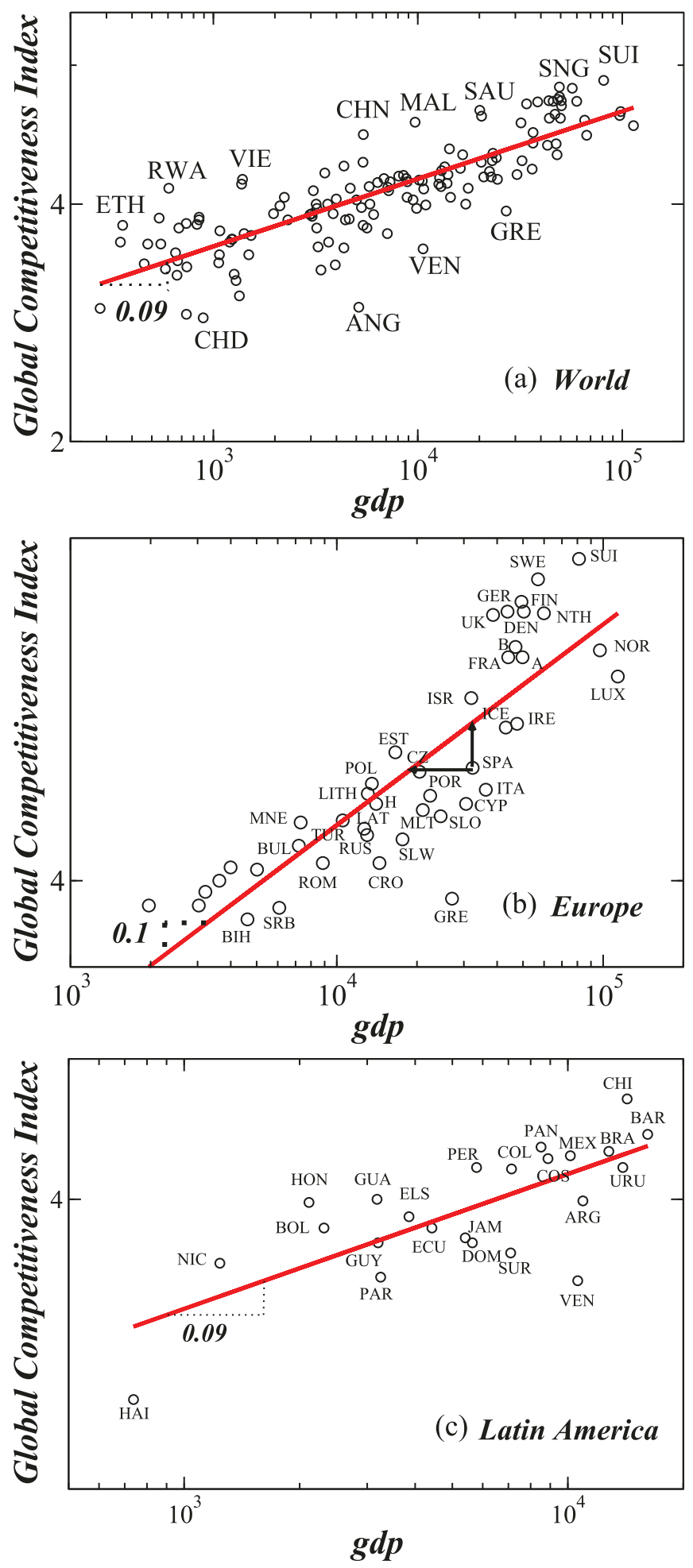

Figure 1 Relative competitiveness measured by GCI versus GDP per capita (gdp) for (a) World, (b) European and (c) Latin American countries. Above (below) the power-law fitting line, the level of competitiveness is more (less) than we expect for the given country wealth, quantified by $g d p$. In (b) Israel is shown, but does not contribute to the fitting line.

$$
\mathrm{GCI} \propto(g d p)^{\alpha}
$$

with exponent $\alpha \approx 0.1$. Figure $1(\mathrm{~b})$ shows that Germany is more competitive than Estonia, but that is to be expected since the German $g d p$ is much larger than the Estonian $g d p$. But is Germany more competitive with its peer countries-those with a comparable $g d p$-than Estonia with its peer countries? When comparing competitiveness relative to $g d p$, how do we estimate which countries are better performers and which are worse? In addressing this question, note that the power-law dependence in Fig. 1(b) indicates the expected level of competitiveness for a given level of country wealth. When a country appears above the fitting line, its level of competitiveness relative to $g d p$ is greater than expected for a country with its given wealth level, quantified by $g d p$. In contrast, countries below the fitting line are less competitive than expected for a country with its given wealth level. This information is valuable for investors who need to assess which countries with comparable $g d p$ values to choose for investment opportunities. For example, Fig. 1(b) shows that Poland is more competitive than Croatia, which we would expect since these two countries have similar $g d p$, but the Polish GCI is higher than the Croatian GCI.

The regression we obtain also allows us to compare the relative levels of competitiveness between two countries that belong to two different wealth brackets. To this end, we introduce a measure to assess relative competitiveness

$$
\mathcal{D} \equiv \ln (\mathrm{GCI})-\langle\ln (\mathrm{GCI})\rangle,
$$

i.e., the difference between the actual GCI value and the expected value of GCI obtained from the power-law fitting line. For countries below the power-law regression line, the more negative the difference $\mathcal{D}$, the smaller the relative competitiveness. Figure 1(b) shows that Greece is the least competitive in relative terms among all the European countries, since Greece has the most negative $\mathcal{D}$. Note that Norway seems to be an outlier among the Nordic countries, but Norway is a huge exporter of oil and thus perhaps does not need to be competitive. Thus for a country below the regression line (see Spain), Fig. 1 suggests (a) the expected level of competitiveness a country should aspire to in order to achieve at least the average relative competitiveness (the vertical line), and (b) where the country may end up if it does not improve its competitiveness (the horizontal line toward the left).

For Latin American countries Fig. 1(c) shows a power law for the GCI versus $g d p$ with an exponent $\alpha=0.09 \pm 0.02$, a value virtually identical to $\lambda$ found for the entire world and for the European countries, implying universality in the regression of Eq. (1). Note that the country with the lowest GCI value, Venezuela, is a huge exporter of oil.

Up to this point no temporal dependence has been included (year 2011), and we have used a "static" approach in assessing levels of competitiveness. Figure 1 suggests that, in order to become a rich country, an initially poor country must improve its competitiveness, but a static approach does not tell us how quickly this can be achieved. In order to demonstrate the benefit of having a more competitive economy, we use a "dynamic" approach to focus on economic growth during recession years. We focus on recession years because during good years even countries with weak growth policies, e.g., countries that use massive indebtedness to increase their GDP, may experience economic expansion.

In order to test how the level of competitiveness affects the dynamics of a country's wealth during an economic downturn, we divide the European countries into two subsets: (i) countries with better than average relative competitiveness, for which $\mathcal{D}$ defined in Eq. (2) is positive, and (ii) countries with less than average relative competitiveness, for which $\mathcal{D}$ is negative. We apply the statistic for the difference between means and find that during the 2008-2011 period, countries with a positive $\mathcal{D}$ experienced a smaller drop in $g d p$ than countries with a negative $\mathcal{D}$, where the $t$-statistic yields $2.57\left(d_{f}\right.$ $=40$ ) suggesting that the difference between these two groups is significant. Figure 2 shows the $g d p$ growth rate vs. $\mathcal{D}$ defined in Eq. (2) for each of the European countries. Note that it is clearly advantageous to be better than average. For the regression line we obtain a slope of $0.54 \pm 0.20$. For the EU countries, including Croatia, during 


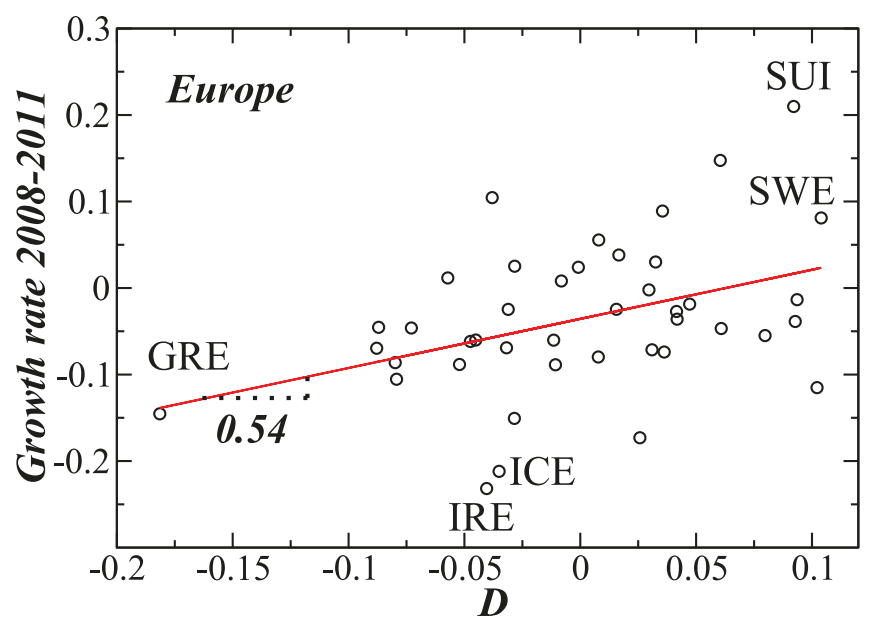

Figure $2 \mid$ Good to be better than the average during an economic downturn 2008-2011. The more positive the relative competitiveness $\mathcal{D}$ of Eq. (2), the larger $g d p$ growth rate for the given period.

the 2008-2011 period, the $g d p$ growth rate vs. $\mathcal{D}$ yields a slope of 0.35 \pm 0.17 .

Addressing question (ii), policymakers need to be able to estimate the probability that a country will improve its wealth position within the next 10 years-e.g., will move from "developing" to "developed" status. The long-range data show that only a few countries, e.g., Singapore and the Republic of Korea, have been able to move from undeveloped to highly developed during a period of only a few decades. Such an occurrence can be justifiably classified a rare event. How probable is it that a poor country such as Peru will become a rich country like the USA within a decade? For both academics and policymakers, quantifying that probability is a problem that deserves much attention.

To determine this probability we apply Zipf ranking ${ }^{16-21}$ to $g d p$ over the 32-year period 1980-2011 $1^{14}$. For each year $t$ we rank $g d p$ for an unchanging group of 137 countries from poorest to richest. The smaller the rank $R_{i}$, the larger the $g d p$, implying that the decrease in rank, $\Delta R<0$, corresponds to an improvement in country wealth. Using overlapping windows for each initial year $t$ we calculate the change in rank, $\Delta R$, for each country over a decade, from $t$ to $t+10$. Figure 3 shows that the probability distribution function (pdf) that a

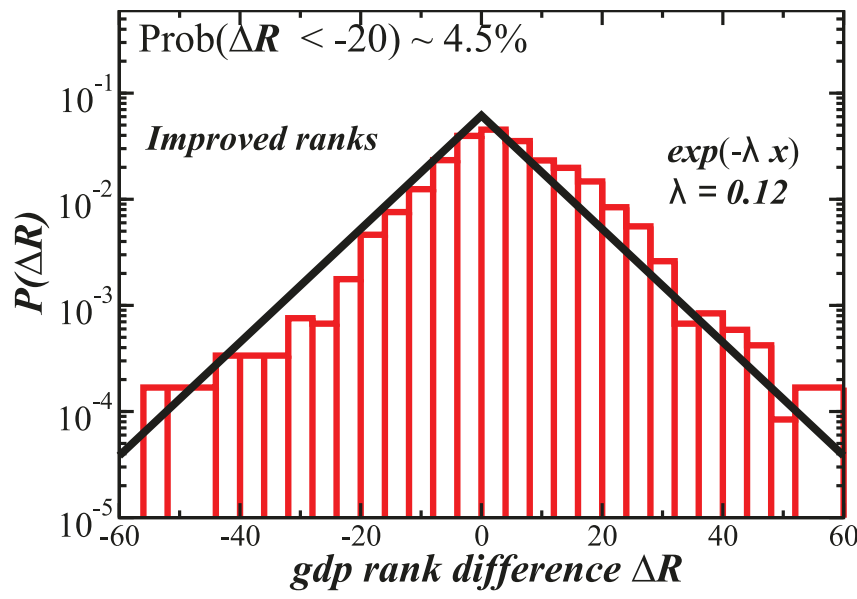

Figure 3 Predictive power of dynamical ranking approach: Probability that a country increases $(\Delta R<0)$ or decreases $(\Delta R>0)$ its wealth quantified by its per capita GDP ( $g d p)$ rank within a 10 -year period. Pdf follows an exponential distribution obtained by maximum likelihood approach with decay constant 0.12 . randomly chosen country will increase its wealth-quantified by its rank-within a decade follows a double exponential distribution

$$
P(\Delta R)=\lambda / 2 \exp (-\lambda|\Delta R|)
$$

with decay constant $\lambda \equiv N / \Sigma_{i}\left|\Delta R_{i}\right|=0.12$ obtained by applying a maximum likelihood, which provides useful information for policymakers. Note that the left and right tails in Fig. 3 correspond to countries whose wealth improves or worsens, respectively. To estimate the probability that Bulgaria's $g d p$ will reach Germany's $g d p$ in 10 years, we calculate $\Delta R$-the difference between the current Bulgarian rank and German rank-and, using Fig. 3 and Eq. (3), we determine the probability $0.5 \exp (-\lambda|\Delta R|)$ that at least a change in rank $\Delta R$ will occur within 10 years.

We begin by assuming that there is a relationship between the competitiveness and the economic growth of a given country. To explain why the probability that the wealth ranking of a country will substantially change over a decade is low, we study the probability that GCI values will change over the same period. Because we lack GCI data over the 10-year period, we study a pdf of changes in GCI rank for 124 countries during the 6-year period 2005-2011. Although we use GCI data for a period that differs from the one we used in Fig. 3, Fig. 4(a) shows the pdf of changes in GCI rank with an exponent similar to the one in Fig. 3, implying that the dynamics of $g d p$ and the dynamics of GCI may share the same origin. We approximate the pdf with an exponential function obtained by using a maximum likelihood approach. Because the GCI value for any given country includes the corruption level of that country, it is reasonable to assume that the dynamics of the Corruption Perceptions Index $(\mathrm{CPI})^{22-24}$ approximates the dynamics of GCI. Thus for European countries GCI versus CPI follows a power law with a slope $3.17(t$ value 13.1) with a correlation coefficient of 0.90 .

Figure 4(b) shows the 2011 CPI versus the $2011 \mathrm{gdp}$ for the EU countries. Because corruption strongly affects a country's prospects for improvement in its wealth rank over a decade (Fig. 3), we next study how corruption changes over time. Figure 4(c) shows a pdf of changes in CPI rank over the period 2001-2011 for 91 countries. In agreement with Fig. 3, which shows the rank of country's wealth, Fig. 4(c) shows that it is improbable that a country will rapidly improve its corruption rank. Again we approximate the pdf of changes in CPI rank with an exponential function and obtain the exponent $\kappa=0.13$, similar to the exponent we found in Fig. 3, implying that the dynamics of $g d p$ and the dynamics of CPI may share the same origin.

Figure 4(c) shows that during the period 2001-2011 the largest decreases in CPI rank among the EU countries occurred in Italy (from rank 29 to 45 ) and in Greece (from rank 42 to 51). In Italy the CPI decreased from 5.2 to 3.9, in Greece from 4.2 to 3.4, in Spain from 7.1 to 6.2 , and, surprisingly, in the UK from 8.7 to 7.8. The largest increase in CPI occurred in Poland (from 4.0 to 5.5), Estonia (from 5.6 to 6.4), and Germany (from 7.3 to 8.0). During the last decade, the CPI values of the majority of the EU countries changed only slightly. A change in nation's mentality in this regard appears to be another rare event. It is not surprising that the countries with the sharpest drops in CPI, e.g., Greece and Italy, now face the most dangerous public debt crises. This is important information for financial institutions, since such countries-those with a sharp drop in $\mathrm{CPI}$-become increasingly risky financially over time.

Finally, to relate indebtedness and competitiveness, Fig. 5 shows for 2011 total exports (both goods and services) ${ }^{25}$ versus total public debt $^{26}$, both calculated as a percentage relative to a country's GDP. Clearly, the total export over GDP may be considered another measure of a nation's competitiveness. Note that most of the Mediterranean countries are characterized by a very small total export relative to GDP, which means that they are generally not very competitive. Some of them, e.g., Greece and Italy, are also highly indebted. 

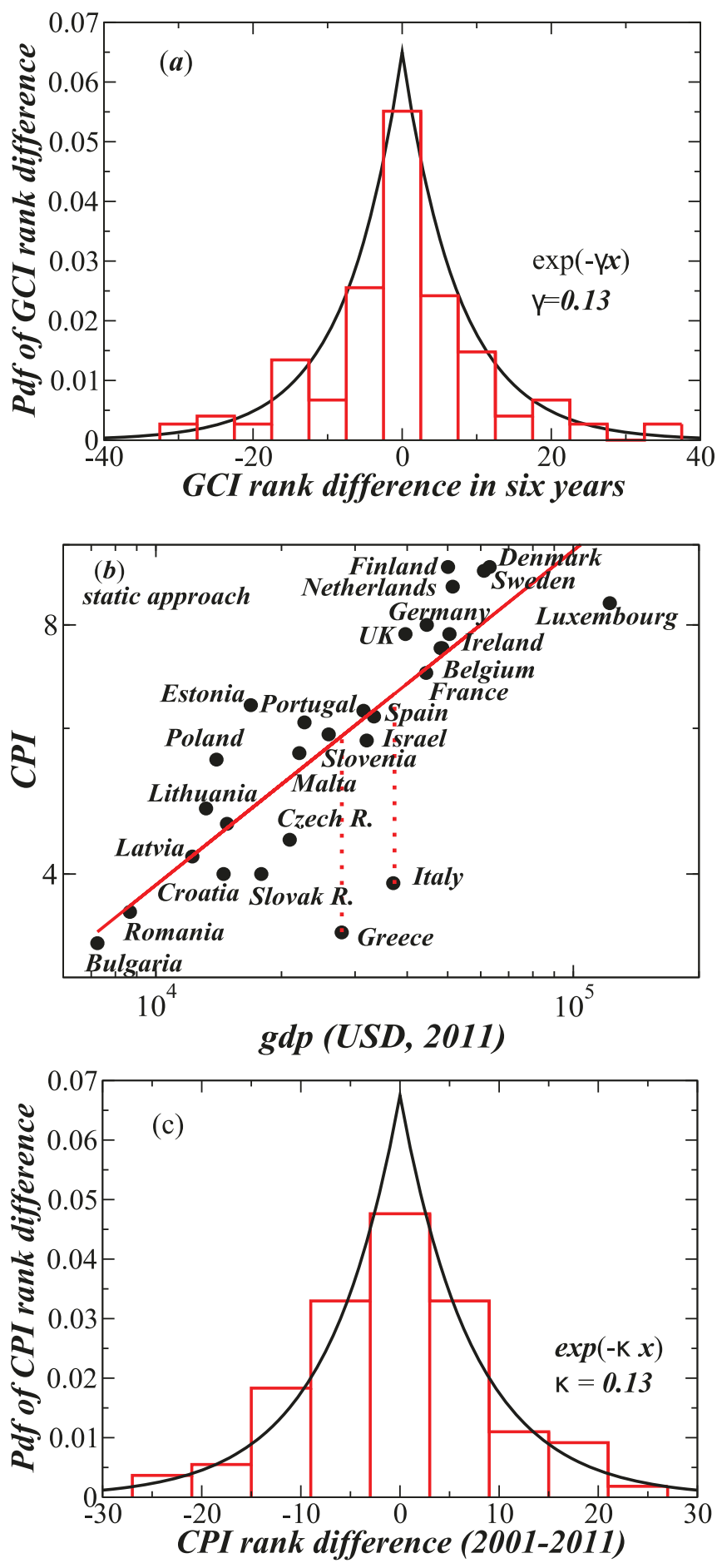

Figure $4 \mid$ Quantifying the Interplay of the Competitiveness, Corruption, and Growth of a Country. We show (a) a pdf of change in GCI rank between 2005 and 2011 for 124 countries for which the data we have in this range; (b) corruption relative to country's wealth for EU members including Croatia that will join EU in 2013; (c) pdf of change in CPI rank for 91 countries for which the data we have in 2001 . We show that the decay constant $\gamma$ of the change in GCI rank and $\kappa$ of the change in CPI rank are in agreement with the decay constant in Fig. 3. Pdfs in (a) and (c) approximately follow exponential distributions obtained by maximum likelihood approach. In (b) Israel is shown but does not contribute to the fit.

Modeling political corruption. Many factors such as education, technological progress, macroeconomic stability, good governance, business firm sophistication, and market efficiency affect productivity and competitiveness ${ }^{2-9,27-33}$. Here we focus on how political corruption affects the growth of a country's wealth ${ }^{34}$.

Suppose an imaginary country has only public sector jobs and that there are only two of them: butchers and neurosurgeons. Having the butchers butcher and the neurosurgeons perform neurosurgery is clearly more efficient than vice versa. In our simplified modeling of political corruption as an aspect of GCI, each country is of the same size but the more developed countries have a highly educated and skilled population. Our model is partially influenced by jobmatching models for the private sector ${ }^{35,36}$. In our model, each country has jobs $X_{i}$ taken from a Poisson distribution that is characterized by a single parameter $\mu$ where, for example, the USA has a larger $\mu$ than Albania. In a country with no political corruption [see Fig. 6(a)], the labor force is optimally distributed, i.e., a worker with skills $x_{i}$ occupies an optimal job $X_{i}$, where $x_{i}=X_{i}$, and this holds for every $i$. In a corrupt country [see Fig. 6(b)], people are often given public sector jobs because of political corruption, nepotism, and bribery, not because they have the skills. Thus countries with political corruption are not as efficient in terms of per capita GDP as countries without corruption.

To model political corruption and nepotism in the public sector (see Fig. 1), we assume that at each time $i$ a new job, $X_{i}$ is created, taken from a Poisson distribution, where the larger the Poisson variable $X_{i}$, the more skilled the labor required by the position. Thus job $X_{i}$ can be held by a worker where $x_{i}=X_{i}$ (he/she is qualified), where $x_{i}>X_{i}$ (over-qualified), and also where $x_{i}<X_{i}$ (under-qualified). We assume that the cases $x_{i}>X_{i}$ and $x_{i}<X_{i}$ are less than optimal, i.e., $x_{i}$ $=X_{i}$. It is clear that when $x_{i}<X_{i}$ (the under-qualified case) the worker will not be as effective as when $x_{i}=X_{i}$, but also that when $x_{i}>X_{i}$ the worker will lack motivation and be less efficient. Specifically, we assume that each worker $x_{i}$ in the public sector works at a job $X_{i}$ where there is a discrepancy $\left(x_{i} \neq X_{i}\right)$ controlled by a Gaussian distribution centered at $X_{i}$ with a standard deviation $\sigma$. This choice of mean $\left(X_{i}\right)$ allows that, when $\sigma=0$ and the country has no corruption, for each $i, x_{i}=X_{i}$ (see Fig. 6), and workers will be optimally distributed to jobs. As $\sigma$ increases, political corruption increases. For each $i$, there is a discrepancy given by

$$
\delta_{i}=\exp \left(-\left|x_{i}-X_{i}\right|\right)
$$

and this functional dependence value allows $\delta_{\mathrm{i}} \in[0,1]$. Utilizing Ref.[34,37], the total discrepancy in the group with $N$ agents is

$$
E=\sum_{i=1}^{N} \delta_{i}
$$

The entire group produces output (GDP) as a function of $E$, where we assume

$$
\mathrm{GDP}=\mu E,
$$

where $g d p=\mathrm{GDP} / N$ and $\mu$ comes from the Poisson distribution of jobs $X_{i}$ introduced above. Note that for a country with no corruption $-\sigma=0$, implying $\delta_{i}=0$ for each $i-$ Eqs. (4) and (5) yield $E=N$, and Eq. (6) yields maximum GDP. We introduce $\mu$ in Eq. (6) because if we compare a country with no corruption but with badly educated and unskilled citizens with $\mu_{1}$ with a country with no corruption but with very educated and highly skilled citizens with $\mu_{2}$, where $\mu_{1}<\mu_{2}$, it must hold that $\mathrm{GDP}_{1}<\mathrm{GDP}_{2}$. Note that Eq. (6) in our framework relates the country wealth, the educational and skills level, and the corruption level, quantified by GDP, $\mu$ and $E$ respectively.

We assume that different countries will differ in skill levels $\mu$ according to a Poisson distribution and in corruption levels quantified by $\sigma$ of a Gaussian distribution. Figure 7 shows 1000 countries each with 10,000 jobs where $\mu$ ranges from 5 to 20 , and $\sigma$ from 0.5 to 20 , both taken from uniform distributions. Note that GCI is defined such that, as it increases, corruption in a given country decreases ${ }^{1}$. We define a theoretical GCI as $\mathrm{GCI}_{t h}=\sigma^{-\gamma}$. With this expression in which $\gamma=0.1$, we obtain a power-law dependence between $\mathrm{GCI}_{t h}$ 


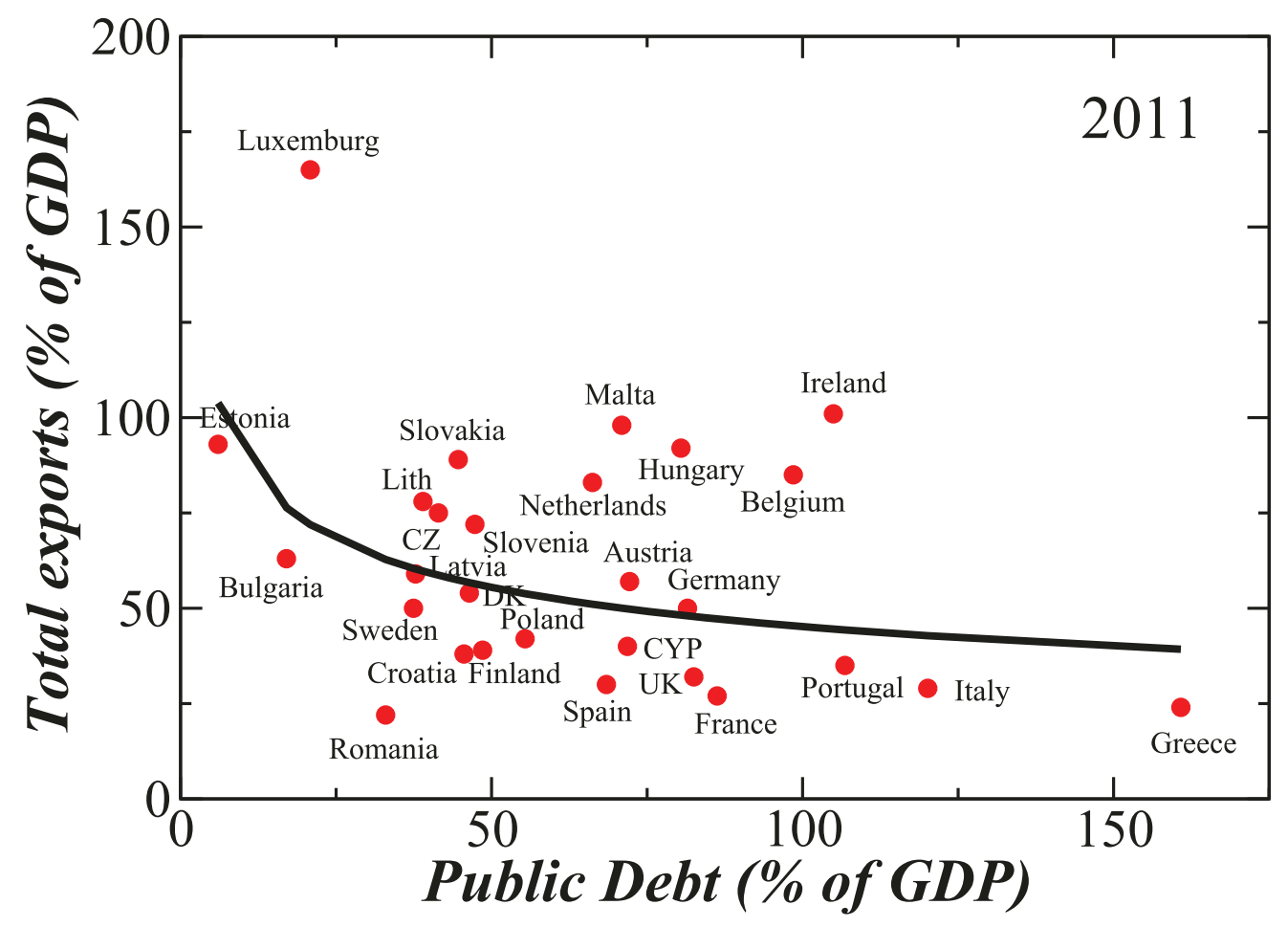

Figure $5 \mid$ Total export versus public debt, both as a percentage of GDP. We fit the plot with a power law and obtain exponent $-0.30 \pm 0.14$.

and $g d p$, similar to the one obtained in Fig. 1. As $\mathrm{GCI}_{t h}$ increases, $g d p$ also increases. Clearly, by tuning parameter $\gamma$ in $\mathrm{GCI}_{t h}=1 / \sigma^{\gamma}$, we can obtain any slope between $\mathrm{GCI}_{t h}$ and $g d p$ we want.

Note that in order to model Fig. 3, we should assume that the $\mu$ and $\sigma$ of different countries change over time. Also note that here we have modeled only the public sector and its contribution to GDP, but we could have easily included the private sector in our analysis. For example, Jovanovic ${ }^{38}$ has proposed a theory of selection in which the key is firm efficiency and how it affects firm growth.

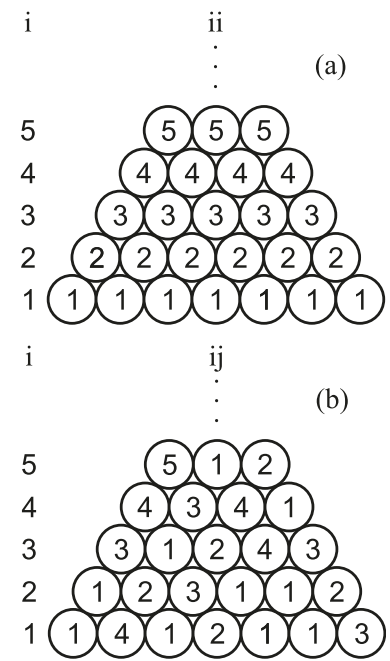

Figure 6 | Model cases of political corruption where jobs are characterized by different level of skills. (a) Political corruption does not exist, since a person with skills $x_{i}$ occupies an optimal position $X_{i}$, where $x_{i}$ $=X_{i}$. In contrast, in (b) political corruption exists since generally $x_{i} \neq X_{i}$. Job place $X_{i}$ can be occupied by either over-qualified $\left(x_{i}>X_{i}\right)$ or underqualified $\left(x_{i}<X_{i}\right)$ person.

\section{Discussion}

What can policymakers do to substantially increase their country's wealth? It was reported that institutional integrity strongly affects competitiveness and growth ${ }^{39}$. In addition, government attitudes toward markets and freedoms and the efficiency of its operations are also very important: excessive bureaucracy, over-regulation, corruption, dishonesty in dealing with public contracts, and political dependence of the judicial system impose significant economic costs to businesses and slow the process of economic development ${ }^{1}$. Potential investors are also unwilling to invest if their rights as owners are not properly protected. Furthermore, the extent of centralization of a given market in both the public and private sectors greatly impacts the competitiveness and economic development within a

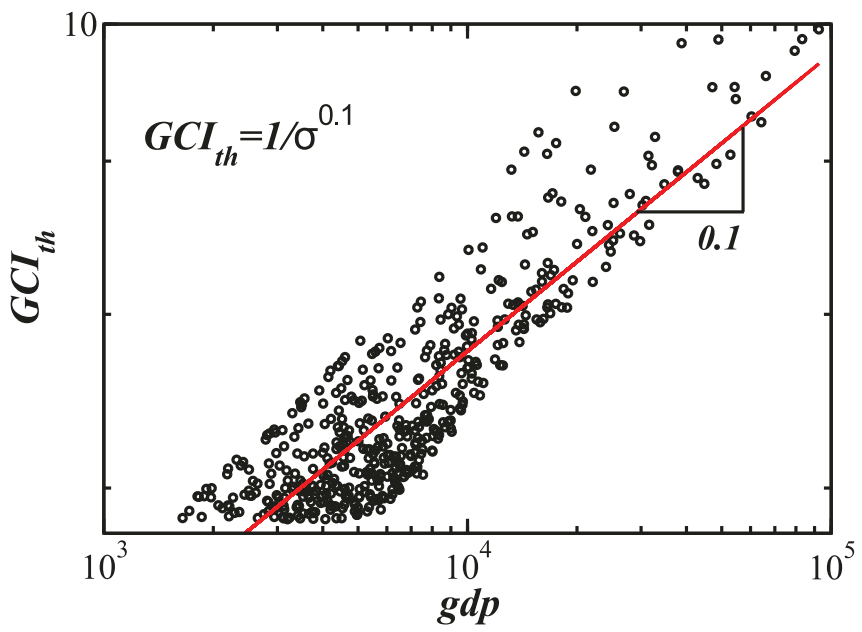

Figure $7 \mid$ Modeling how well a society is organized quantified by parameter $\boldsymbol{\sigma}$. Model simulations for $\mathrm{GCI}_{t h} \mathrm{vs}$. model GDP. We define theoretical CPI as $\mathrm{GCI}_{t h} \equiv 1 / \sigma^{\gamma}$. By varying $\gamma$ we change the slope between $\mathrm{GCI}_{t h}$ and $g d p$. 
given country. Thus a highly centralized private market can be as problematic as a highly centralized public sector.

Figure 3 shows that it is highly improbable that a country will experience a substantial increase in its wealth. There are many reasons for this ${ }^{40}$. One of the most important is that to experience a substantial increase in wealth a nation must change its collective behavior. It must, for example, reduce its levels of nepotism and corruption [see Fig. 4(b)]. We might imagine a country in which all citizens are equally educated and equally skilled. In such a case, political corruption would not affect growth. In real-world corrupt countries, however, we can assume that the less-skilled job holders are more politically connected than the more-skilled job holders. Political corruption and nepotism can also account for the difference in effectiveness between public and private sectors, because in corrupt countries many of the public sector jobs are held by those who are politically connected, irrespective of their qualifications-a majority of political party members hold public sector jobs they would not have if they were not party members. An ineffective public sector often generates an increase in public debt and, as the public debt level increases, the government must consider raising taxes. Raising taxes then can substantially affect the economy's competitiveness. Thus a country's level of corruption can determine how the country is organized and how efficient its government is, which, in turn, affects the private sector that pays the government's bills.

Interdependent groups of countries such as the EU seem to be more vulnerable to financial fluctuations than independent single countries, a finding that is agreement with recent studies of interdependent networks ${ }^{41-45}$. Recently, in order to increase the competitiveness of the EU and reduce its financial vulnerability, many EU politicians have been advocating not just a continuation of the currency union, but also the creation of a fiscal union. Before this is attempted, a common mechanism to control corruption at the EU level is needed, e.g., an anti-nepotism law. If corruption is allowed to continue and grow, un-corrupt EU countries will increasingly be paying the bills of the corrupt. Fighting corruption is thus fighting for an increase in competitiveness, and this must be a top EU priority.

\section{Methods}

The World Economic Forum has released the Global Competitiveness Index (GCI), developed by Sala-i-Martin and Artad, in order to assess the ability of countries to provide high levels of prosperity for their citizens ${ }^{1}$. The index quantifies how productive a country is as it uses available resources. It measures the microeconomic and macroeconomic foundations of national competitiveness. GCI is defined as a weighted average of many different components, each measuring a different aspect of competitiveness: institutions, infrastructure, macroeconomic environment, health, primary education, goods market efficiency, labor market efficiency, financial market development, technological readiness (e.g., access to high technology), market size, business sophistication, and innovation ${ }^{1}$. It provides a raw score that ranges between 0 and 6 , where the later value defines the most competitive country. The 2011-2012 Global Competitiveness Report covers 142 developed and developing economies.

We also analyze the Corruption Perceptions Index (CPI $)^{22,23}$ introduced by Transparency International. The CPI is a composite index based on independent surveys of business people and on assessments of corruption in different countries provided by more than ten independent institutions around the world, including the World Economic Forum, the United Nations Economic Commission for Africa, and the Economist Intelligence Unit. The CPI ranges from 0 (highly corrupt) to 10 (highly transparent).

1. Schwab, K. The Competitiveness Report 2011-2012 (World Economic Forum, Geneva, 2012).

2. Schultz, T. W. Investment in human capital. American Economic Review 1, 1 (1961).

3. Romer, P. M. The origins of endogenous growth. The Journal of Economic Perspectives 8, 3 (1994).

4. Lucas, R. E. On the mechanics of economic development. Journal of Monetary Economics 22, 3 (1988).

5. Fischer, S. The role of macroeconomic factors in growth. Journal of Monetary Economics 32, 485 (1993).

6. Alesina, A., Spolaore, E. \& Enrico, R. Endogenous Growth (Cambridge, MA: MIT Press, 1998).

7. Barro, R. J. \& Sala-i-Martin, X. X. Economic Growth (MIT Press, London, 1995).

8. Sala-i-Martin, X. X. The classical approach to convergence analysis. Economic Journal 106, 1019 (1996).
9. Solow, R. M. A contribution to the theory of economic growth. Quarterly Journal of Economics 70, 65 (1956).

10. Quah, D. Galton's fallacy and the convergence hypothesis. Scandinavian J. of Economics 95, 427 (1993).

11. Bernard, A. B. \& Durlauf, S. N. Interpreting tests of the convergence hypothesis. Journal Econometrics 71, 161 (1996).

12. Sachs, J. D. \& Warner, A. M. Fundamental sources of long-run growth. American Economic Review 87, 184 (1997).

13. Sala-i-Martin, X. X. The world distribution of income: Falling poverty and ... convergence, period. Quarterly Journal of Economics 121, 351 (2006).

14. http://www.imf.org/ (accessed on 21-06-2012).

15. Sala-i-Martin, X. X. \& Artadi, E. V. The Global Competitiveness Index, Global Competitiveness Report (Global Economic Forum 2004).

16. Zipf, G. K. Human Behavior and the Principle of Least Effort (Addison-Wesley, New York, 1949).

17. Stanley, M. H. R. et al. Zipf plots and the size distribution of firms. Economics Lett. 49, 453 (1995).

18. Gabaix, X. Zipf's law for cities: An explanation. Quarterly J. Economics 114, 739 (1999).

19. Axtell, R. L. Zipf distribution of U.S. firm sizes. Science 293, 1818 (2001).

20. Podobnik, B., Horvatic, D., Petersen, A. M., Urosevic, B. \& Stanley, H. E. Bankruptcy risk model and empirical tests. Proc. Natl. Acad. Sci. USA 107, 18325 (2010).

21. Podobnik, B., Valentincic, A., Horvatic, D. \& Stanley, H. E. Asymmetric Levy flight in financial ratios. Proc. Natl. Acad. Sci. USA 108, 17883 (2011).

22. http://cpi.transparency.org/ (accessed on 21-06-2012).

23. Shao, J., Ivanov, P. Ch., Podobnik, B. \& Stanley, H. E. Quantitative relations between corruption and economic factors. Eur. Phys. J. B 56, 157 (2007).

24. Podobnik, B., Shao, J., Njavro, D., Ivanov, P. Ch. \& Stanley, H. E. Influence of corruption on economic growth rate and foreign investments. Eur. Phys. J. B 63, 547 (2008).

25. http://data.worldbank.org/indicator/ (accessed on 21-06-2012).

26. http://epp.eurostat.ec.europa.eu/portal/page/portal/eurostat/home/ (accessed on 21-06-2012).

27. Delli Gatti, D., Gallegati, M. \& Mignacca, D. Nonlinear Dynamics and European GNP Data. Studies in Nonlinear Dynamics and Econometrics 3, 3 (1998).

28. Garlaschelli, D., Di Matteo, T., Aste, T., Caldarelli, G. \& Loffredo, M. I. Interplay between topology and dynamics in the World Trade Web. Eur. Phys. J. B 57, 159 (2007).

29. Ausloos, M. \& Lambiotte, R. Clusters or networks of economies? A macroeconomy study through Gross Domestic Product. Physica A 382, 16 (2007).

30. Clementi, F., Di Matteo, T., Gallegati, M. \& Kaniadakis, G. The $\kappa$-generalized distribution: A new descriptive model the size distribution of incomes. Physica A 387, 3201 (2008).

31. Shao, J., Ivanov, P. Ch., Urosevic, B., Stanley, H. E. \& Podobnik, B. Zipf rank approach and cross-country convergence of incomes. EPL 94, 48001 (2011).

32. Hidalgo, C. A., Klinger, B., Barabasi, A. \& Hausmann, R. The Product Space Conditions the Development of Nations. Science 317, 482 (2007).

33. Hidalgo, C. A. \& Hausmann R. The building blocks of economic complexity. Proc. Natl. Acad. Sci. U.S.A. 10610570 (2009).

34. Pluchino, A., Rapisarda, A. \& Garofalo, C. The Peter principle revisited: a computational study. Physica A 389, 467 (2010).

35. Miller, R. A. Job Matching and Occupational Choice. Journal of Political Economy 92, 1086 (1984).

36. Jovanovic, B. Job Matching and the Theory of Turnover. The Journal of Political Economy 87, 972 (1979).

37. Axtell, R. L. The emergency of firms in population of agents. (Working Papers 9903-019, Santa Fe Institute).

38. Jovanovic, B. Selection and the evolution of industry. Econometrica 50, 649 (1982).

39. Acemoglu, D., Johnson, S. \& Robinson J. The colonial origins of comparative development: An empirical investigation. American Economic Review 91, 1369 (2001)

40. Preis, T., Moat, H. S., Stanley, H. E. \& Bishop, S. R. Quantifying the advantage of looking forward. Sci. Rep. 2, 350 (2012).

41. Buldyrev, S. V., Parshani, R., Paul, G., Stanley, H. E. \& Havlin, S. Catastrophic cascade of failures in interdependent networks. Nature 464, 1025 (2010).

42. Vespignani, A. The Fragility of interdependency. Nature 464, 984 (2010).

43. Gao, J., Buldyrev, S. V., Stanley, H. E. \& Havlin, S. Networks formed from interdependent networks. Nature Physics 8, 40 (2012).

44. Kenett, Y. D., Raddant, M., Lux, T. \& Ben-Jacob, E. Evolvement of uniformity and volatility in the stressed global financial village. PLoS ONE 7, e31144 (2012).

45. Kenett, Y. D., Raddant, M., Zatlavi, L., Lux, T. \& Ben-Jacob, E. Correlations in the global financial village. International Journal of Modern Physics Conference Series 16, $13(2012)$

\section{Acknowledgments}

We thank the ONR and the Keck Foundation for financial support.

\section{Author contributions}

$\mathrm{BP}, \mathrm{DH}$, and DYK performed analyses, and $\mathrm{BP}, \mathrm{DH}, \mathrm{DYK}$ and HES discussed the results, and contributed to the text of the manuscript. 


\section{Additional information}

Competing financial interests: The authors declare no competing financial interests. License: This work is licensed under a Creative Commons

Attribution-NonCommercial-ShareAlike 3.0 Unported License. To view a copy of this license, visit http://creativecommons.org/licenses/by-nc-sa/3.0/
How to cite this article: Podobnik, B., Horvatić, D., Kenett, D.Y. \& Stanley, H.E. The competitiveness versus the wealth of a country. Sci. Rep. 2, 678; DOI:10.1038/srep00678 (2012). 